Article

\title{
Neighboring Hetero-Atom Assistance of Sacrificial Amines to Hydrogen Evolution Using Pt-Loaded $\mathrm{TiO}_{2}$-Photocatalyst
}

\author{
Masahide Yasuda ${ }^{1{ }^{1} *}$, Takayuki Tomo ${ }^{1}$, Shoichi Hirata ${ }^{1}$, Tsutomu Shiragami ${ }^{1}$ \\ and Tomoko Matsumoto ${ }^{2}$ \\ 1 Department of Applied Chemistry, Faculty of Engineering, University of Miyazaki, \\ Gakuen-Kibanadai Nishi, Miyazaki 889-2192, Japan; E-Mails: tt.6521.totoro@gmail.com (T.T.); \\ tb13016@student.miyazaki-u.ac.jp (S.H.); t0g109u@cc.miyazaki-u.ac.jp (T.S.) \\ 2 Center for Collaborative Research and Community Cooperation, University of Miyazaki, \\ Gakuen-Kibanadai Nishi, Miyazaki 889-2192, Japan; E-Mail: t-matsu@cc.miyazaki-u.ac.jp \\ * Author to whom correspondence should be addressed; E-Mail: yasuda@cc.miyazaki-u.ac.jp; \\ Tel.:+81-985-7314.
}

Received: 27 February 2014; in revised form: 12 May 2014 / Accepted: 13 May 2014 /

Published: 26 May 2014

\begin{abstract}
Photocatalytic $\mathrm{H}_{2}$ evolution was examined using Pt-loaded $\mathrm{TiO}_{2}$-photocatalyst in the presence of amines as sacrificial agents. In the case of amines with all of the carbon attached to the hetero-atom such as 2-aminoethanol, 1,2-diamonoethane, 2-amino-1,3-propanediol, and 3-amino-1,2-propanediol, they were completely decomposed into $\mathrm{CO}_{2}$ and water to quantitatively evolve $\mathrm{H}_{2}$. On the other hand, the amines with both hetero-atoms and one methyl group at the $\beta$-positions (neighboring carbons) of amino group such as 2-amino-1-propanol and 1,2-diaminopropane were partially decomposed. Also, the photocatalytic $\mathrm{H}_{2}$ evolution using amines without the hetero-atoms at the $\beta$-positions such as ethylamine, propylamine, 1-butylamine, 1,3-diaminopropane, 2-propylamine, and 2-butylamine was inefficient. Thus, it was found that the neighboring hetero-atom strongly assisted the degradation of sacrificial amines. Moreover, rate constants for $\mathrm{H}_{2}$ evolution were compared among amines. In conclusion, the neighboring hetero-atom did not affect the rate constants but enhanced the yield of hydrogen evolution.
\end{abstract}

Keywords: $\mathrm{TiO}_{2}$; photocatalytic hydrogen evolution; amines; structural dependence of sacrificial agents; neighboring hetero-atom assistance; kinetic analysis 


\section{Introduction}

Hydrogen production from water has received a great amount of interest in development of a renewable and clean energy source [1]. Titanium oxide $\left(\mathrm{TiO}_{2}\right)$-photocatalytic reaction has been one promising approach to hydrogen production since the discovery of photoelectrochemical hydrogen evolution with $\mathrm{TiO}_{2}$ by Honda and Fujishima [2]. The $\mathrm{TiO}_{2}$-photocatalytic reaction is initiated by charge-separation into electrons and holes $\left(\mathrm{h}^{+}\right)$under irradiation [3]. The electron reduces water to generate $\mathrm{H}_{2}$ while $\mathrm{h}^{+}$oxidizes the $\mathrm{HO}^{-}$to give a hydroxyl (HO) radical [4]. It is well known that the use of electron-donating sacrificial agents remarkably accelerates the $\mathrm{TiO}_{2}$-photocatalyzed hydrogen evolution since the $\mathrm{HO}^{\circ}$ radical is consumed by the sacrificial agents [5]. Therefore, the selection of sacrificial agents will strongly affect the efficiency of the hydrogen evolution. Recently, we have found that sacrificial agents with all of the carbon attached the hydroxy groups such as saccharides (e.g., glucose and xylose) and polyalcohols (1,2-ethandiol, glycerol, arabitol) and continued to serve as an electron source until their sacrificial ability was exhausted in the photocatalytic hydrogen evolution by Pt-loaded $\mathrm{TiO}_{2}\left(\mathrm{Pt} / \mathrm{TiO}_{2}\right)$ [6-8]. Thus, it was found that a neighboring oxygen-atom substituted at $\beta$-position strongly assisted the decarboxylation from alcoholic sacrificial agents [8]. On the other hand, it is well known that amines are good electron-donating sacrificial agents [9]. However, the degradation process of the amine is still insufficient to be elucidated. Here, the degradation process of the amines in the photocatalyic $\mathrm{H}_{2}$ evolution using the $\mathrm{Pt} / \mathrm{TiO}_{2}$ was examined by a quantitative and a kinetic analysis in order to examine whether or not neighboring oxygen-atom affects the yield and the rate of $\mathrm{H}_{2}$ evolution.

\section{Results}

\subsection{Yields of $\mathrm{H}_{2}$ and $\mathrm{CO}_{2}$ Evolved from the Photocatalytic Reaction}

Table 1 lists the sacrificial agents such as amine and carboxylic acid used in the photocatalytic $\mathrm{H}_{2}$ evolution. Recently we have elucidated that the alcohols, the carbons of which all have hydroxyl groups, were completely decomposed into $\mathrm{CO}_{2}$ and water by the $\mathrm{TiO}_{2}$ photocatalytic reaction [8]. Therefore, the amines used in the present study were classified into three groups (Groups A, B and C) from the substituent positions of the hetero-atoms such as $\mathrm{O}$ and $\mathrm{N}$. Group A involved the amines with all of the carbon-substituted hetero-atoms. Group B involved the amines with both continuous hetero-atom-substituted carbon and one non-hetero-atom-substituted carbon (methyl group). Group C involved the amines without the hetero-atoms at the $\beta$-position of amino group.

An aqueous solution $(150 \mathrm{~mL})$ containing varying amounts of sacrificial agents $(0.25-1.25 \mathrm{mmol})$ and $\mathrm{Pt} / \mathrm{TiO}_{2}(100 \mathrm{mg})$ was irradiated under vigorous stirring with a magnetic stirrer for $14-160 \mathrm{~h}$ until the gas evolution ceased. The evolved gas was analyzed by GLC and the gas volumes of $\mathrm{H}_{2}$ and $\mathrm{CO}_{2}$ evolved from given amounts of sacrificial agents are summarized in Supporting Information (Table S1). A typical example can be observed in the results of 1,2-diaminoethane (1a) where the evolved $\mathrm{H}_{2}$ increased as increase of the amounts of 1a used. However, the molar ratio of the evolved $\mathrm{H}_{2}$ to $1 \mathrm{a}$ $\left(\mathrm{H}_{2} / \mathbf{1 a}\right)$ was dependent on the amount of $\mathbf{1 a}$ used. Therefore, the $\mathrm{H}_{2} / \mathbf{1 a}$ was plotted against the molar ratio of $1 \mathbf{a}$ to the catalyst (1a/catalyst) which was adjusted to $0.2,0.4,0.6,0.8$, and 1.0, as shown in Figure 1. As the 1a/catalyst decreased, the $\mathrm{H}_{2} / \mathbf{1 a}$ values increased. The intercept of the plots 
represented a limiting amount of $\mathrm{H}_{2}\left(\mathrm{H}_{2}{ }^{\mathrm{max}}\right)$ obtained from one mole of sacrificial agent at an infinite amount of the catalyst.

Table 1. Yields and rate constants for $\mathrm{Pt} / \mathrm{TiO}_{2}$-photocatalytic hydrogen evolution using sacrificial amines and carboxylic acids.

\begin{tabular}{|c|c|c|c|c|c|c|c|}
\hline \multicolumn{3}{|c|}{ Sacrificial agents } & \multirow{2}{*}{$\begin{array}{c}\mathrm{H}_{2}^{\max } \\
/ \mathrm{mol} \mathrm{mol}^{-1} \\
\end{array}$} & \multirow{2}{*}{$\begin{array}{c}\mathrm{CO}_{2}{ }^{\max } \\
/ \mathrm{mol} \mathrm{mol}^{-1}\end{array}$} & \multirow{2}{*}{$\begin{array}{c}\mathrm{CH}_{4}{ }^{\max } \\
/ \mathrm{mol} \mathrm{mol}^{-1}\end{array}$} & \multirow{2}{*}{ Yield $/ \%^{a}$} & \multirow{2}{*}{$k / h^{-1}$} \\
\hline Run & Formula & $\boldsymbol{P}_{\mathbf{E}}$ & & & & & \\
\hline \multicolumn{8}{|c|}{ Amines with all of carbons attached hetero-atom (Group A) } \\
\hline 1 & $\mathrm{H}_{2} \mathrm{NCH}_{2} \mathrm{CH}_{2} \mathrm{NH}_{2}(\mathbf{1 a})$ & 10 & 5.2 & 2.1 & 0 & 100 & 3.84 \\
\hline 2 & $\mathrm{MeNH}_{2}(\mathbf{1 b})$ & 6 & 2.9 & 1.0 & 0 & 97 & 3.83 \\
\hline 3 & $\mathrm{HOCH}_{2} \mathrm{CH}_{2} \mathrm{NH}_{2}(\mathbf{1} \mathbf{c})$ & 10 & 5.0 & 1.8 & 0 & 100 & 7.64 \\
\hline 4 & $\left(\mathrm{HOCH}_{2}\right)_{2} \mathrm{CHNH}_{2}(\mathbf{1 d})$ & 14 & 7.0 & 2.5 & 0 & 100 & 6.70 \\
\hline 5 & $\mathrm{HOCH}_{2} \mathrm{CH}(\mathrm{OH}) \mathrm{CH}_{2} \mathrm{NH}_{2}(\mathbf{1 e})$ & 14 & 6.4 & 1.8 & 0 & 91 & 7.64 \\
\hline \multicolumn{8}{|c|}{ Amines with both hetero-atoms and methyl group at $\beta$-positions (Group B) } \\
\hline 6 & $\mathrm{MeCH}\left(\mathrm{NH}_{2}\right) \mathrm{CH}_{2} \mathrm{OH}(\mathbf{1 f})$ & 16 & 3.8 & 0.7 & 0 & 48 & 9.43 \\
\hline 7 & $\mathrm{MeCH}\left(\mathrm{NH}_{2}\right) \mathrm{CH}_{2} \mathrm{NH}_{2}(\mathbf{1 g})$ & 16 & 4.0 & 0 & 0 & 50 & 3.93 \\
\hline \multicolumn{8}{|c|}{ Amines without hetero-atom at $\beta$-positions (Group C) } \\
\hline 8 & $\mathrm{MeCH}_{2} \mathrm{NH}_{2}(\mathbf{1 h})$ & 12 & 3.3 & 0.5 & 0 & 55 & 5.21 \\
\hline 9 & $\mathrm{MeCH}_{2} \mathrm{CH}_{2} \mathrm{NH}_{2}(\mathbf{1 i})$ & 18 & 4.0 & 0.0 & 0 & 44 & 4.09 \\
\hline 10 & $\mathrm{MeCH}_{2} \mathrm{CH}_{2} \mathrm{CH}_{2} \mathrm{NH}_{2}(\mathbf{1} \mathbf{j})$ & 24 & 4.1 & 0.1 & 0 & 34 & 2.53 \\
\hline 11 & $\mathrm{H}_{2} \mathrm{NCH}_{2} \mathrm{CH}_{2} \mathrm{CH}_{2} \mathrm{NH}_{2}(\mathbf{1 k})$ & 16 & 4.6 & 0.0 & 0 & 58 & 6.23 \\
\hline 12 & $\mathrm{MeCH}\left(\mathrm{NH}_{2}\right) \mathrm{Me}(\mathbf{1 1})$ & 18 & 2.4 & 0.0 & 0 & 27 & 6.70 \\
\hline 13 & $\mathrm{MeCH}_{2} \mathrm{CH}\left(\mathrm{NH}_{2}\right) \mathrm{Me}(\mathbf{1} \mathbf{m})$ & 24 & 3.3 & 0.0 & 0 & 25 & 2.40 \\
\hline \multicolumn{8}{|c|}{ Carboxylic acids and carbonyl compounds } \\
\hline 14 & $\mathrm{HCO}_{2} \mathrm{H}(\mathbf{2 a})$ & 2 & 1.0 & 1.0 & 0 & 100 & 4.88 \\
\hline 15 & $\mathrm{HO}_{2} \mathrm{CCO}_{2} \mathrm{H}(\mathbf{2} \mathbf{b})$ & 2 & 1.0 & 2.0 & 0 & 100 & 0.76 \\
\hline 16 & $\mathrm{HO}_{2} \mathrm{CCH}_{2} \mathrm{OH}(\mathbf{2 c})$ & 6 & 2.8 & 1.8 & 0 & 93 & 6.38 \\
\hline 17 & $\mathrm{MeCO}_{2} \mathrm{H}(\mathbf{2 d})$ & 8 & 2.9 & 1.7 & 0.27 & 100 & 0.07 \\
\hline 18 & $\mathrm{MeCOCH}_{2} \mathrm{OH}(\mathbf{2 e})$ & 14 & 4.9 & 2.5 & 0.30 & 89 & 0.34 \\
\hline 19 & $\mathrm{MeCH}(\mathrm{OH}) \mathrm{CO}_{2} \mathrm{H}(\mathbf{2 f})$ & 12 & 4.1 & 2.3 & 0.30 & 88 & 12.48 \\
\hline 20 & $\mathrm{MeCOCO}_{2} \mathrm{H}(\mathbf{2 g})$ & 10 & 3.9 & 2.7 & 0.30 & 102 & 0.37 \\
\hline 21 & $\mathrm{CH}_{2}\left(\mathrm{CO}_{2} \mathrm{H}\right)_{2}(\mathbf{2 h})$ & 8 & 2.6 & 2.7 & 0.31 & 96 & 0.10 \\
\hline 22 & $\mathrm{MeCH}_{2} \mathrm{CO}_{2} \mathrm{H}(\mathbf{2 i})$ & 14 & 2.3 & 1.0 & 0 & 33 & 0.18 \\
\hline
\end{tabular}

${ }^{\mathrm{a}}$ Yield $=100\left(2 \mathrm{H}_{2}{ }^{\max }+8 \mathrm{CH}_{4}{ }^{\max }\right) / P_{\mathrm{E}} ;{ }^{\mathrm{b}}$ Rate constants for $\mathrm{H}_{2}$ evolution.

Also, the amounts of the evolved $\mathrm{CO}_{2}$ were dependent on the amount of sacrificial agents used. The plots of the molar ratio of $\mathrm{CO}_{2}$ to $\mathbf{1 a}\left(\mathrm{CO}_{2} / \mathbf{1 a}\right)$ against $\mathbf{1 a}$ /catalyst are shown in Figure 1. From the intercept of the plots, the limiting amount of $\mathrm{CO}_{2}\left(\mathrm{CO}_{2}{ }^{\mathrm{max}}\right)$ from one mole of $\mathbf{1 a}$ was obtained. Thus, the 1a was decomposed by $\mathrm{HO}^{\circ}$ radical to five equivalents of $\mathrm{H}_{2}$ and two equivalents of $\mathrm{CO}_{2}$.

Similar treatments were applied to other sacrificial agents. The $\mathrm{H}_{2}{ }^{\mathrm{max}}$ and $\mathrm{CO}_{2}{ }^{\mathrm{max}}$ are summarized in Table 1. In many cases, the $\mathrm{CO}_{2}$ evolved from the amines was smaller than the case of carboxylic acids. The resulting $\mathrm{CO}_{2}$ might be partially trapped with $\mathrm{NH}_{3}$ or amines in aqueous solution to form $\mathrm{RNH}_{3}{ }^{+} \mathrm{HCO}_{3}{ }^{-}$[10]. If sacrificial agents which have formula $\mathrm{C}_{n} \mathrm{H}_{m} \mathrm{~N}_{p} \mathrm{O}_{q}$, is entirely decomposed into $\mathrm{CO}_{2}, \mathrm{NH}_{3}$, and $\mathrm{H}_{2} \mathrm{O}$ by $\mathrm{HO}^{\circ}$ radical (Equation (1)), the sacrificial agents will be capable of serving as $4 n+m-3 p-2 q$ electron sources. We defined these $4 n+m-3 p-2 q$ values as the potentially 
electron-donating ability $\left(P_{\mathrm{E}}\right)$ of sacrificial agents. In other words, sacrificial agent theoretically has the ability to evolve $(4 n+m-3 p-2 q) / 2$ equivalents of the $\mathrm{H}_{2}$ in the $\mathrm{TiO}_{2}$-photocatalytic reaction. The $P_{\mathrm{E}}$ values are listed in Table 1 . The $\mathrm{H}_{2}$ evolution yield was defined to be $100 \times 2 \mathrm{H}_{2}{ }^{\max } / \mathrm{P}_{\mathrm{E}}$.

$$
\begin{gathered}
\mathrm{C}_{n} \mathrm{H}_{m} \mathrm{~N}_{p} \mathrm{O}_{q}+(4 n+m-3 p-2 q) \mathrm{HO} \cdot \rightarrow n \mathrm{CO}_{2}+p \mathrm{NH}_{3}+(2 n+m-3 p-q) \mathrm{H}_{2} \mathrm{O} \\
P_{\mathrm{E}}=4 n+m-3 p-2 q
\end{gathered}
$$

Figure 1. Plots of $\mathrm{H}_{2} / \mathbf{1 a}(\bullet)$ and $\mathrm{CO}_{2} / \mathbf{1 a}(\Delta)$ against $\mathbf{1 a}$ /catalyst in $\mathrm{TiO}_{2}$-photocatalytic reaction of 1,2-aminoethane (1a).

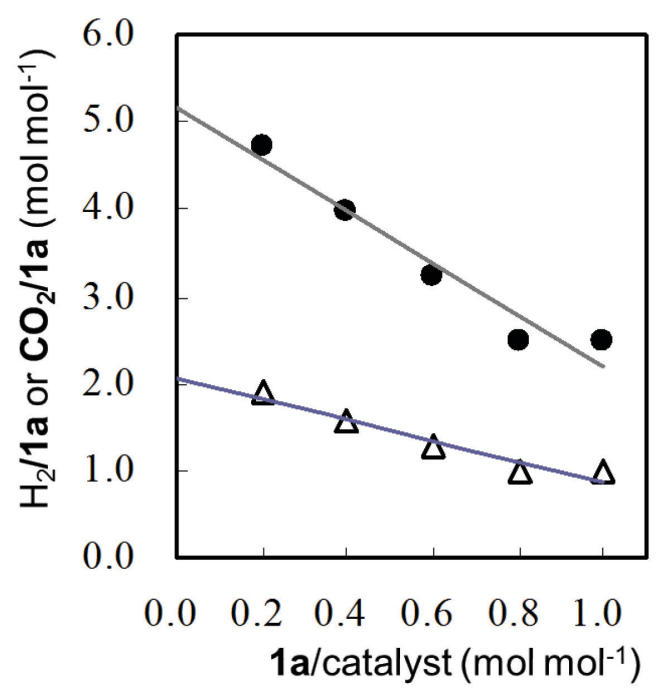

Figure 2. Degradation scheme of amine (1) by $\mathrm{HO}^{\bullet}$ radical.

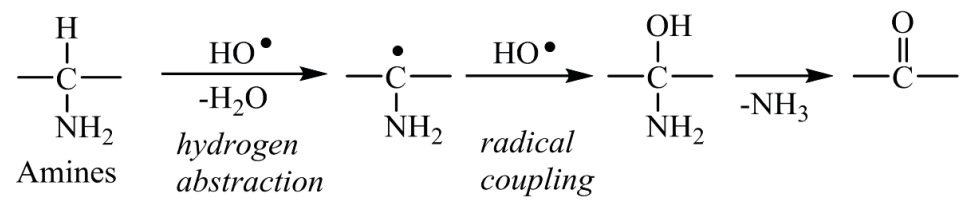

\subsection{Kinetic Analysis of Hydrogen Evolution}

Figure 2 shows the degradation scheme of the amines by $\mathrm{HO}^{\bullet}$ radical. The $\mathrm{HO}^{\bullet}$ radical abstracted a hydrogen atom from the $\alpha$-carbon of the amines, and the resulting radicals underwent to radical coupling with $\mathrm{HO}^{\circ}$ radical [11]. Elimination of ammonia occurred to form the carbonyl groups. The evolution of one equivalent of $\mathrm{H}_{2}$ corresponded to the consumption of two equivalent of $\mathrm{HO}^{\bullet}$ radicals and one equivalent of sacrificial agent. Therefore, the rate of $\mathrm{H}_{2}$ evolution can be presented by Equation (2). It was suggested that the concentration of $\mathrm{HO}^{\circ}$ radical ([HO$\left.{ }^{\circ}\right]$ ) was constant under same irradiation conditions. Therefore, pseudo-first order rate constant $(k)$ for $\mathrm{H}_{2}$ evolution can be determined by the plots of $-\ln (1-V / 22.4)$ against the irradiation time $(t)$ where $V$ was the gas volume in $\mathrm{mL}$ evolved from $1 \mathrm{mmol}$ of sacrificial agent at each irradiation time (Equation (3)). In the case of carboxylic acids, two equivalent $\mathrm{HO}^{\circ}$ radicals induced to evolution of one equivalent of $\mathrm{CO}_{2}$ along with one equivalent of $\mathrm{H}_{2}$. The $k$ values were determined according to the plots of $-\ln (1-V / 44.8)$ against the irradiation time. 


$$
\begin{gathered}
\text { rate }=d\left[\mathrm{H}_{2}\right] / d \mathrm{t}=k^{\prime}\left[\mathrm{HO}^{\circ}\right]^{2}[\text { amine }]=k[\text { amine }], \text { where }[\text { amine }]=1-\left[\mathrm{H}_{2}\right] \\
-\ln (1-V / 22.4)=k t
\end{gathered}
$$

\section{Discussion}

\subsection{Degradation Mechanism of Carboxylic Acids (2a-i)}

Several kinds of carboxylic acids and carbonyl compounds (2a-i) which were thought to be intermediates in the degradation process of the amines were subjected to the photocatalytic $\mathrm{H}_{2}$ evolution. Formic acid (2a), oxalic acid (2b), and glycolic acid (2c) were completely decomposed to $\mathrm{CO}_{2}$ and water along with the formation of $\mathrm{H}_{2}$ in almost quantitative yields (runs 14-16). On the other hand, acetic acid (2d) was decomposed into $\mathrm{CO}_{2}$ and water along with the formation of methane (run 17), as has been reported by Zheng et al. [12]. Therefore, the limiting amount of $\mathrm{CH}_{4}\left(\mathrm{CH}_{4}{ }^{\mathrm{max}}\right)$ from one mole of 1c was obtained from the intercept of the plots of the molar ratio of $\mathrm{CH}_{4}$ to $\mathbf{1 c}\left(\mathrm{CH}_{4} / \mathbf{1 c}\right)$ against $\mathbf{1 c}$ /catalyst. $2 \mathbf{d}$ was thought to consume 5.8 equivalents of $\mathrm{HO}$ radicals to produce $1.7 \mathrm{CO}_{2}$ and $0.3 \mathrm{CH}_{4}$, since 2.9 equivalents of $\mathrm{H}_{2}$ were evolved. Therefore, decomposition scheme of $\mathbf{2} \mathbf{d}$ is written as Figure 3. 1-Hydroxy-2-propanone (2e) consumed 9.8 equivalents of $\mathrm{HO}^{\circ}$ radicals to produce $2.5 \mathrm{CO}_{2}$ and $0.30 \mathrm{CH}_{4}$ (run 18). Also lactic acid (2f) consumed 8.2 equivalents of $\mathrm{HO}^{\circ}$ radicals to produce $2.3 \mathrm{CO}_{2}$ and $0.30 \mathrm{CH}_{4}$ (run 19). Pyruvic acid (2g) consumed 7.8 equivalents of $\mathrm{HO}^{\circ}$ radicals to produce $2.7 \mathrm{CO}_{2}$ and $0.30 \mathrm{CH}_{4}$ (run 20). Malonic acid (2h) consumed 5.2 equivalents of $\mathrm{HO}^{\circ}$ radicals to produce $2.7 \mathrm{CO}_{2}$ and $0.31 \mathrm{CH}_{4}$ (run 21). Since the decomposition of $\mathbf{2 d - h}$ by $\mathrm{HO}^{\bullet}$ radical occurred along with the formation of methane, the degradation of $\mathbf{2} \mathbf{f}-\mathbf{h}$ proceeded through $\mathbf{2} \mathbf{e}$ (Figure 3 ). The yields from $\mathbf{2} \mathbf{d}-\mathbf{h}$ were calculated to be near $100 \%$ according to the equation: Yield $=100 \times\left(2 \mathrm{H}_{2}{ }^{\mathrm{max}}+8 \mathrm{CH}_{4}{ }^{\mathrm{max}}\right) / \mathrm{P}_{\mathrm{E}}$.

\subsection{Degradation Mechanism of Amines (1a-i)}

At first, we checked whether initial hydrogen abstraction occurs at $\alpha$-hydrogen of amino group or amino group itself, since amino group is good sacrificial agent. The photocatalytic $\mathrm{H}_{2}$ evolution was performed using $t$ - $\mathrm{BuNH}_{2}$ which had no $\alpha$-hydrogen as sacrificial agent. $\mathrm{H}_{2}$ was evolved from $t$ - $\mathrm{BuNH}_{2}\left(H_{2}{ }^{\max }=1.0\right)$ whereas $\mathrm{H}_{2}$ was not evolved from t-BuOH $\left(H_{2}{ }^{\max }=0\right)$. Also the photocatalytic reaction using $\mathrm{NH}_{3}$ as sacrificial agents evolved $\mathrm{H}_{2}$. Therefore, hydrogen abstraction from amino group occurred resulting in the oxidation of amino group. However, H-abstraction from amino group was slower than the $\mathrm{H}$-abstraction from the $\alpha$-carbons of amine and alcohols [13]. Moreover, the photocatalytic $\mathrm{H}_{2}$ evolution using methylamine (1b) produced in 3.0 of $\mathrm{H}_{2}{ }^{\max }$ values (Table 1, run 1). Nitoromethane was not formed from $\mathbf{1 b}$. Therefore, we thought that the degradation of $\mathbf{1 b}$ proceeded through the formation of formaldehyde and formic acid (2a) in a similar manner to the case of methanol [14,15] (Figure 4), although the oxidation of amino group of methylamine has been reported [16,17]. This suggested that the amino group was not oxidized in the case of usual 1 having hydrogen at the $\alpha$-carbons. 
Figure 3. Decomposition of carboxylic acid $(\mathbf{2} \mathbf{d}-\mathbf{h})$ by $\mathrm{HO}^{\bullet}$ radical.

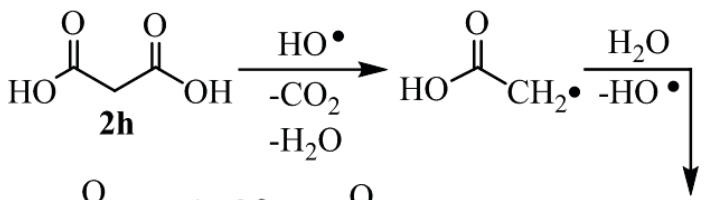

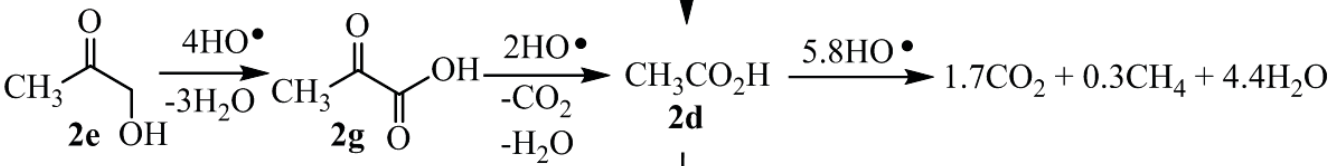

$$
\begin{aligned}
& \overbrace{\mathbf{2 f} \mathrm{O}}^{\mathrm{OH}} \frac{2 \mathrm{HO} \bullet}{-2 \mathrm{H}_{2} \mathrm{O}}
\end{aligned}
$$

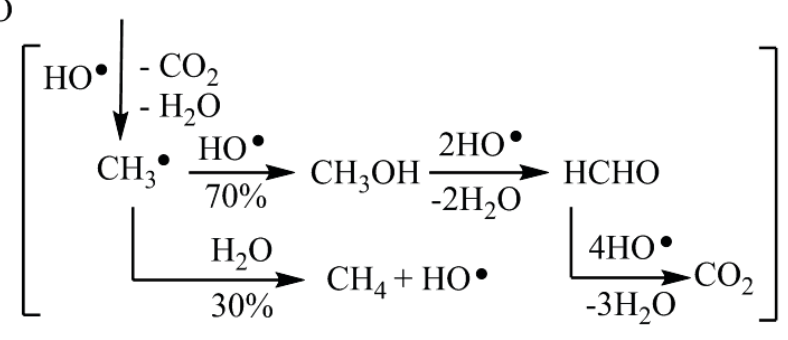

Figure 4. Decomposition of methylamine (1b) and formic acid (2a) by $\mathrm{HO}^{\bullet}$ radical.

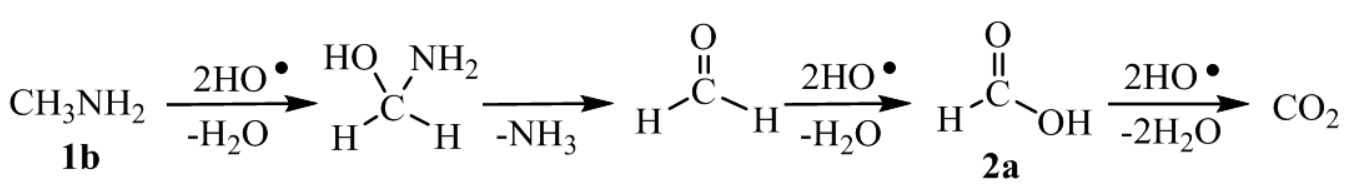

In Group A, 1a and 2-aminoethanol (1c) whose $\mathrm{H}_{2}{ }^{\mathrm{max}}$ were 5.0-5.2 were completely decomposed by $\mathrm{HO}^{\circ}$ radicals (runs 1 and 3). These results suggested that the decomposition proceeded through the formation of $\mathbf{2 b}$ (Figure 5). Also, 2-amino-1,3-propanediol (1d) and 3-amino-1,2-propanediol (1e) were completely decomposed via $\mathbf{2 b}$ (runs $4-5$ ) in a similar manner to the case of glycerol [18]. Thus, in the cases of $\mathbf{1 b}-\mathbf{e}$ with all of the carbon attached the hetero atoms (Group A), the decomposition was able to proceed quantitatively. On the other hand, the yields of $\mathrm{H}_{2}$ evolution using Group B such as 2-amino-1-propanol (1f) and 1,2-diaminopropane (1g) did not reach 100\% (runs 6-7), as has been reported for 1,2-propanediol [19]. These were decomposed through the formations of $\mathbf{2 g}$ to give $\mathbf{2 d}$

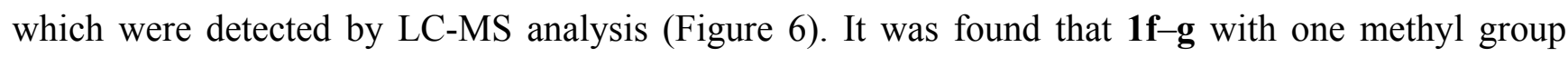
(Group B) did not completely decompose, resulting in $\mathrm{H}_{2}$ in $48-88 \%$ yields. In the case of Group $\mathrm{C}$, ethylamine (1h) and propylamine (1i) were partially decomposed (Figure 7) and the $\mathrm{H}_{2}$ yields did not reach $100 \%$ (run 8 ) in a similar manner to the case of ethanol [20]. The decomposition occurred through the formation of $\mathbf{2 d}$ which could be detected by LC-MS analysis. Butylamine (1j) consumed four equivalents of $\mathrm{HO}^{\circ}$ radicals to give butanoic acid which was slowly decomposed to propanal [21] since butanoic acid was detected by LC-MS (run 10). Also, the 1,3-diaminopropane (1k) consumed eight equivalents of $\mathrm{HO}^{\bullet}$ radicals to give $\mathbf{2} \mathbf{h}$ (run 11). However, it was thought that $\mathbf{2} \mathbf{h}$ smoothly underwent further oxidation to $\mathbf{2 d}$, since $\mathbf{2 h}$ could not be detected by the LC-MS analysis of the photolysates but $\mathbf{2 d}$ was detected. Thus, terminal amines $(\mathbf{1} \mathbf{h}-\mathbf{1 k})$ underwent the partial $\mathrm{CO}_{2}$ evolution (runs 8-11). Carboxylic acid tended to react with amines and/or ammonia to form salts $\left(\mathrm{RNH}_{3}{ }^{+} \mathrm{HCO}_{3}{ }^{-}\right)$ which were inactive toward the $\mathrm{HO}^{\bullet}$ radical. Therefore, the degradation of amines with $\mathrm{HO}^{\circ}$ radical was retarded compared with those of carboxylic acids. The amines, such as 2-propylamine (11) and 2-butylamine (1m), whose amino group attached on secondary carbons, were inefficient (runs 12-13), 
as has been reported for the oxidation of secondary alcohols such as 2-propanol [22] and 2-butanol [22]. Acetone from 11 [23] and 2-butanone from 1m were detected by GLC analysis of photolysates.

Figure 5. Degradation of 1a, $1 \mathbf{c}-\mathbf{e}\left(\right.$ Group A) by $\mathrm{HO}^{\bullet}$ radical.
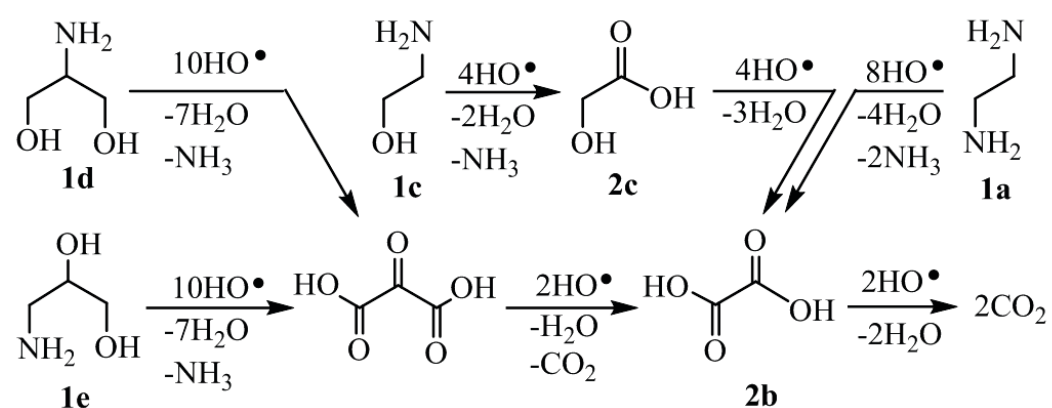

Figure 6. Degradation of $\mathbf{1 f}-\mathbf{g}$ (Group B) by $\mathrm{HO}^{\bullet}$ radical.

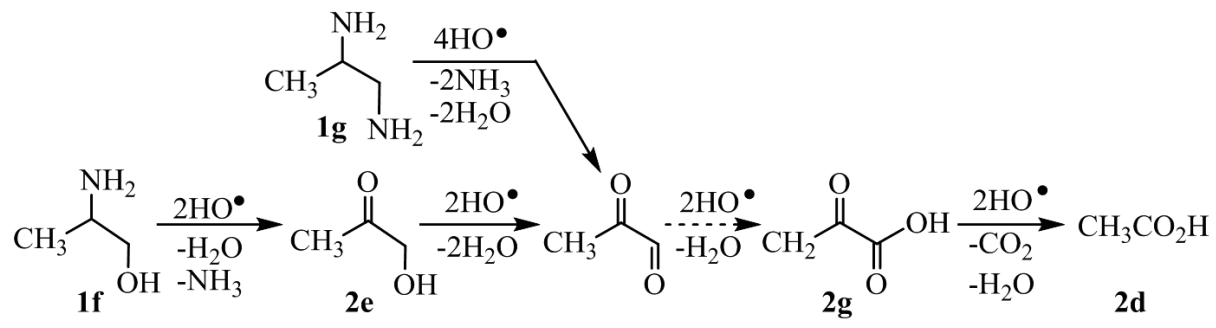

Figure 7. Degradation of $\mathbf{1 h}-\mathbf{m}\left(\right.$ Group C) by $\mathrm{HO}^{\bullet}$ radical.

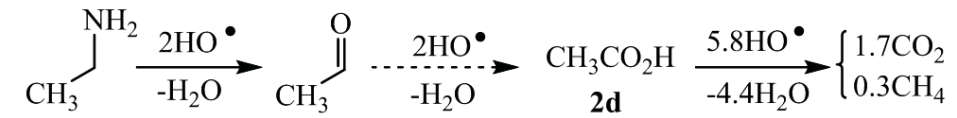

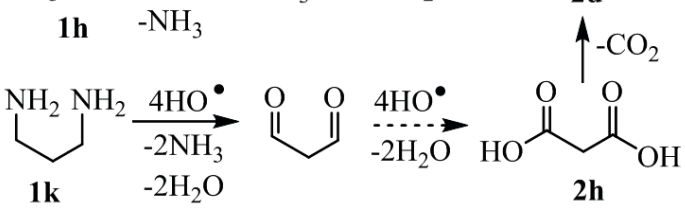

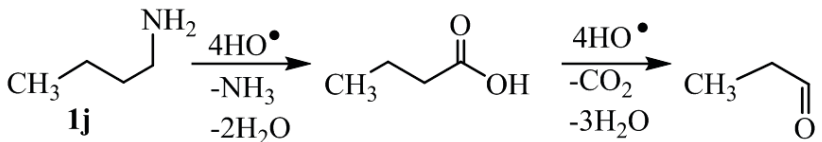

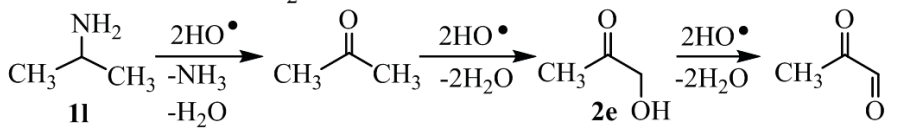

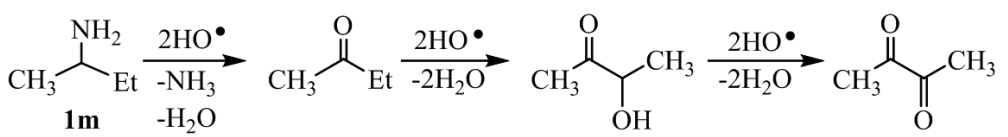

\subsection{Rate Constants for the Hydrogen Abstraction with $\mathrm{HO}^{\circ}$ Radical from $\mathbf{1}$ and $\mathbf{2}$}

As a preliminary experiment, the time-conversion of $\mathrm{H}_{2}$ evolution was examined using three carbons-containing sacrificial agents such as 1-propylamine (1i), propanal, and propanoic acid (2i). According to Figure 8, $\mathbf{1 i}$ was oxidized to propanal which was further oxidized to $\mathbf{2} \mathbf{i}$, which was subjected to the decarboxylation to give ethanol (run 22). The time courses of gas evolution are shown 
in Figure 9. Apparently, gas evolutions from $\mathbf{1 i}$ were faster than that from $2 \mathbf{i}$ (runs 9 and 22). Therefore, the analysis of the $\mathrm{H}_{2}$-evolutions in the amines was safely performed without the effects of the further oxidation of aldehydes and carboxylic acids. The results of rate constants for $\mathrm{H}_{2}$ evolution using a variety of amines are summarized in Table 1. Moreover, the $k$ values $\left(3.83-9.43 \mathrm{~h}^{-1}\right)$ of $\mathbf{1 a}-\mathbf{g}$ which belong to groups A and B were almost same as those $\left(2.40-6.70 \mathrm{~h}^{-1}\right.$ ) of $\mathbf{1 h}-\mathbf{m}$ (Group C). Therefore, neighboring hetero-atoms which are substituted at the $\beta$-positions did not affect the rate constants for hydrogen abstraction from $\alpha$ carbons of the amine.

Figure 8. Degradation of 1-propylamine (1i) and propanoic acid (2i) by $\mathrm{HO}^{\bullet}$ radical.

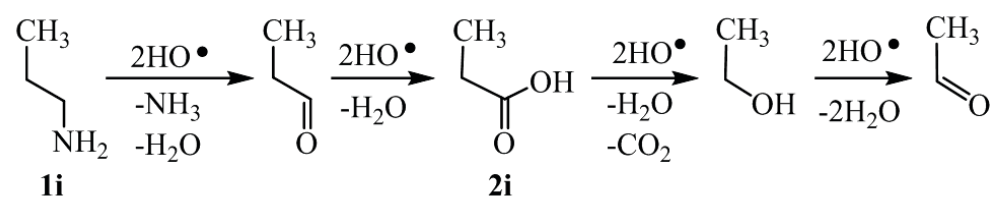

Figure 9. Time-conversion plots of the evolved gas volume $(V)$ in the $\mathrm{Pt} / \mathrm{TiO}_{2}$ photocatalytic reaction using 1-propylamine $(\mathbf{1 i}, \mathbf{a})$, propanal $(\Delta)$, and propanoic acid $(\mathbf{2} \mathbf{i}, \circ)$.

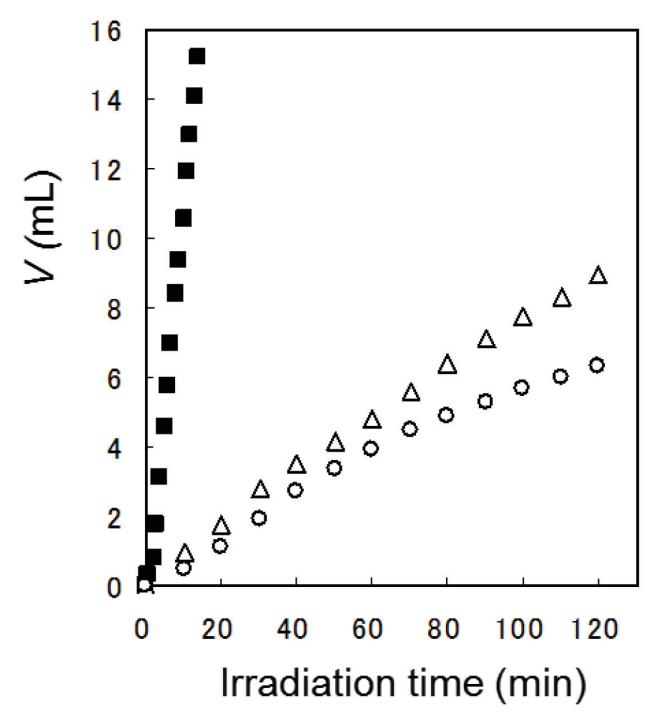

\subsection{Relationship between the Actual Electron-Donating Ability and $P_{E}$ of Sacrificial Agents}

Figure 10 shows plots of the actual electron-donating ability $\left(2 \mathrm{H}_{2}{ }^{\mathrm{max}}\right)$ against the $\mathrm{P}_{\mathrm{E}}$ values in the $\mathrm{Pt} / \mathrm{TiO}_{2}$-photocatalytic $\mathrm{H}_{2}$ evolution using the amines. The amines with all of the carbon attached the hetero-atom (Group A) were completely decomposed into $\mathrm{CO}_{2}$ and water in almost $100 \%$ yields. Group B with both one methyl group and hetero-atoms at the $\beta$-positions of amino and hydroxyl groups (neighboring hetero-atom) and the Group C, without neighboring hetero-atom, were partially decomposed. As has been reported previously for alcoholic sacrificial agents [8], it was found that the neighboring hetero-atom remarkably assisted the decarboxylation from carboxylic acids (Figure 11). The lone pair electrons of the hetero-atom stabilized the radical (3). Therefore, the degradation of sacrificial agents having neighboring hetero-atom proceeded to evolve $\mathrm{H}_{2}$ in high yields. 
Figure 10. Plots of the actual electron-donating ability $\left(2 \mathrm{H}_{2}{ }^{\max }\right)$ against $P_{\mathrm{E}}$ in the $\mathrm{Pt} / \mathrm{TiO}_{2}$-photocatalytic $\mathrm{H}_{2}$ evolution using 1a-m: Group A (०), Group B (a), and Group C $(\Delta)$. A line was $2 H_{2}{ }^{\max }=P_{\mathrm{E}}$.

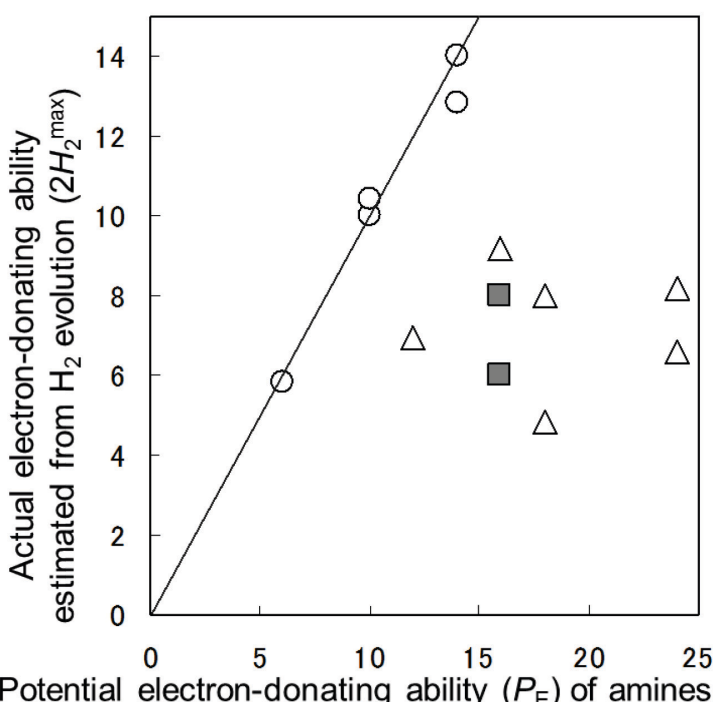

Figure 11. Neighboring hetero-atom assistance to the decarboxylation with $\mathrm{HO}^{\bullet}$ radical.

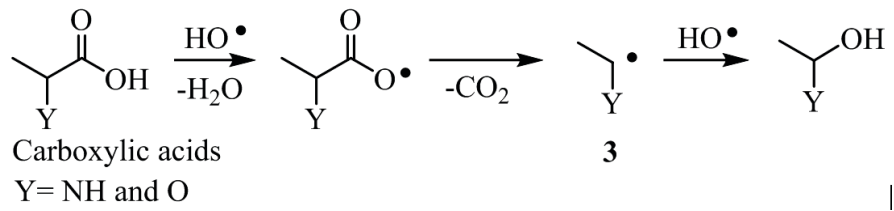

\section{Experimental Section}

\subsection{Preparation of the Photocatalyst}

Anatase-type of $\mathrm{TiO}_{2}$ (Ishihara Sangyo Kasei Ltd. ST-01) was purchased from Ishihara Sangyo, Japan. According to previous research [24], the $\mathrm{Pt} / \mathrm{TiO}_{2}$ was prepared by irradiation of a deaerated aqueous solution $(400 \mathrm{~mL})$ containing $\mathrm{TiO}_{2}(4.0 \mathrm{~g}), \mathrm{K}_{2} \mathrm{PtCl}_{6}(20-200 \mathrm{mg})$, and 2-propanol $(2.4 \mathrm{~g}, 3.0 \mathrm{~mL})$ by high-pressure mercury lamp (100 W, UVL-100HA, Riko, Japan) for $24 \mathrm{~h}$ under stirring. Water was entirely removed from the photolysate by evaporator. The resulting precipitate was washed with water on filter and then dried under reduced pressure to give $\mathrm{Pt} / \mathrm{TiO}_{2}$. The structure of $\mathrm{Pt} / \mathrm{TiO}_{2}$ was analyzed by a Shimadzu (Kyoto, Japan) XRD 7000 diffractometer. Figure 12 shows that an anatase structure of $\mathrm{TiO}_{2}$ was kept after the loading of Pt. The Pt-content of $\mathrm{TiO}_{2}$ was optimized to be $2.0 \mathrm{wt} \%$ by the comparison of $\mathrm{H}_{2}$ amounts evolved from the photocatalytic reaction using the $\mathrm{Pt} / \mathrm{TiO}_{2}$ with different amounts of Pt (1.0-3.0 wt \%), which was performed in the presence of glycerol (115 mg, $1.25 \mathrm{mmol})$ under irradiation for $6 \mathrm{~h}[8]$. 
Figure 12. X-ray diffraction of Pt-loaded $\mathrm{TiO}_{2}$ (red line) and $\mathrm{TiO}_{2}(\mathrm{ST}-01$, orange line).

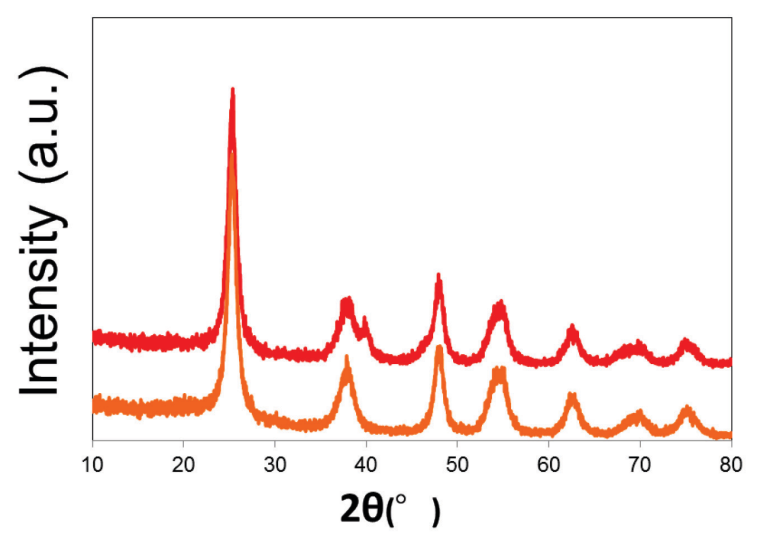

\subsection{Photocatalytic Reaction}

The amines and carboxylic acids were purchased from Wako Chemicals (Osaka, Japan) and used without further purification. The volume of the aqueous solution containing sacrificial agents $(0.25-1.25 \mathrm{mmol})$ was adjusted to $150 \mathrm{~mL}$ by adding water and the solution was introduced into a reaction vessel. The optimized amount of $\mathrm{Pt} / \mathrm{TiO}_{2}(100 \mathrm{mg}, 1.25 \mathrm{mmol})$ was added into a reaction vessel and suspended by vigorous stirring by a magnetic stirrer. A high-pressure mercury lamp (100 W, UVL-100HA, Riko, Chiba, Japan) was inserted into the reaction vessel, which was attached to a measuring cylinder with a gas-impermeable tube to collect the evolved gas. The reaction vessel was set in a water bath to keep it at a constant temperature (usually $20{ }^{\circ} \mathrm{C}$ ). After the $\mathrm{O}_{2}$ was purged from the reaction vessel by $\mathrm{N}_{2}$ gas, irradiation was performed. The evolved gas was collected by the measuring cylinder to measure the volume of the evolved gas. The evolved gas was analyzed on a Shimadzu (Kyoto, Japan) GC-8A equipped with a TCD detector at a temperature raised from $40{ }^{\circ} \mathrm{C}$ to $180{ }^{\circ} \mathrm{C}$ using a stainless column $(3 \mathrm{~mm} \Phi \times 6 \mathrm{~m})$ packed with a SHINCARBON ST (Shimadzu, Kyoto, Japan). $\mathrm{H}_{2}, \mathrm{CO}_{2}$, and methane were detected in addition to $\mathrm{N}_{2}$ which was used as the purging gas.

\subsection{Analysis of Photolysate Solutions}

LC-MS analysis of the photolysate solutions were performed on a Waters Alliance (Tokyo, Japan) 2695 under conditions (ESI ionization, capillary voltage $3.5 \mathrm{kV}$, source temperature $120{ }^{\circ} \mathrm{C}$ and desolvation temperature $350^{\circ} \mathrm{C}$ ) using column (Waters Tokyo, Japan) SunFire (Tokyo, Japan) C18, $2.1 \mathrm{~mm} \Phi \times 150 \mathrm{~mm}$ ) and eluent solution (water). Under these conditions, acetic acid (2d) appeared at 2.10-min retention time where acetic acid had a mass peak at $m / z 60\left(\mathrm{M}^{+}\right)$. Also, propanoic acid (2i, $\left.\mathrm{m} / \mathrm{z} 74\left(\mathrm{M}^{+}\right)\right)$and pyruvic acid $\left(\mathbf{2 e}, \mathrm{m} / \mathrm{z} 88\left(\mathrm{M}^{+}\right)\right)$were detected at $3.16 \mathrm{~min}$ and $2.68 \mathrm{~min}$, respectively. Butanoic acid $\left(\mathrm{m} / \mathrm{z} 71\left(\mathrm{M}^{+}-17\right)\right)$ and malonic acid $\left(\mathbf{2 f}, \mathrm{m} / \mathrm{z} 104\left(\mathrm{M}^{+}\right), 87\left(\mathrm{M}^{+}-\mathrm{OH}\right)\right)$ appeared at $6.20 \mathrm{~min}$ and $2.44 \mathrm{~min}$, respectively. 2-Butaonone and acetone were measured by GLC analysis at a temperature raised from $50{ }^{\circ} \mathrm{C}$ to $250{ }^{\circ} \mathrm{C}$ on a Shimadzu (Kyoto, Japan) 14A with FID detector using a capillary column (J\&W CP-Sil 5CB, Folsom, CA, USA). $32 \mathrm{~mm} \Phi \times 50 \mathrm{~m}$ ). 2-Butaonone and acetone appeared at $10.5 \mathrm{~min}$ and $6.9 \mathrm{~min}$ retention time, respectively. 


\section{Conclusions}

The $\mathrm{Pt} / \mathrm{TiO}_{2}$-photocatalytic $\mathrm{H}_{2}$ evolution was examined using amines as sacrificial agents. The degradation pathways of amines by $\mathrm{HO}^{\bullet}$ radical were elucidated. The yields of the evolved $\mathrm{H}_{2}$ depended on their structure of amines. The presence of neighboring hetero-atom strongly accelerated the decarboxylation, resulting in high yields of $\mathrm{H}_{2}$ evolution. However, the neighboring hetero-atoms did not affect the hydrogen abstraction from $\alpha$ carbons of amines.

\section{Acknowledgments}

This study was partially supported by a Grant-in-Aid for Scientific Research (C) No 24610055 from the Ministry of Education, Culture, Sports, Science, and Technology of Japan.

\section{Author Contributions}

Masahide Yasuda conceived experimental idea and analyzed experimental data. Also Masahide Yasuda prepared the manuscript and revised it. Takayuki Tomo carried out the kinetic analysis. Shoichi Hirata carried out the quantitative analysis of hydrogen evolution under supervision of Tsutomu Shiragami. Tomoko Matsumoto carried out the product analysis and X-ray diffraction.

\section{References}

1. Navarro, R.M.; Peña, M.A.; Fierro, J.L.G. Hydrogen production reactions from carbon feedstocks: Fossil fuels and biomass. Chem. Rev. 2007, 107, 3952-3991.

2. Fujishima, A.; Honda, K. Electrochemical photolysis of water at a semiconductor electrode. Nature 1972, 238, 37-38.

3. Fujishima, A.; Rao, T.N.; Tryk, D.A. Titanium dioxide photocatalysis. J. Photochem. Photobiol. C 2000, 1, 1-21.

4. Galinska, A.; Walendziewski, J. Photocatalytic water splitting over $\mathrm{Pt}_{-} \mathrm{TiO}_{2}$ in the presence of sacrificial reagents. Energy Fuels 2005, 19, 1143-1147.

5. Chheda, J.N.; Huber, G.W.; Dumesic, J.A. Liquid-phase catalytic processing of biomass-derived oxygenated hydrocarbons to fuels and chemicals. Angew. Chem. Int. Ed. 2007, 46, 7164-7183.

6. Shiragami, T.; Tomo, T.; Tsumagari, H.; Yuki, R.; Yamashita, T.; Yasuda, M. Pentose acting as a sacrificial multi-electron source in photocatalytic hydrogen evolution from water by Pt-doped $\mathrm{TiO}_{2}$. Chem. Lett. 2012, 41, 29-30.

7. Shiragami, T.; Tomo, T.; Tsumagari, H.; Ishii, Y.; Yasuda, M. Hydrogen evolution from napiergrass by the combination of biological treatment and a Pt-loaded $\mathrm{TiO}_{2}$-photocatalytic reaction. Catalysis 2012, 2, 56-67.

8. Shiragami, T.; Tomo, T.; Matsumoto, T.; Yasuda, M. Structural dependence of alcoholic sacrificial agents on $\mathrm{TiO}_{2}$-photocatalytic hydrogen evolution. Bull. Chem. Soc. Jpn. 2013, 86, 382-389.

9. Nishimoto, S.-I.; Ohtani, B.; Yoshikawa, T.; Kagiya, T. Photocatalytic conversion of primary amines to secondary amines and cyclization of polymethylene- $\alpha, \omega$-diamines by an aqueous suspension of $\mathrm{TiO}_{2}$ /Pt. J. Am. Chem. Soc. 1983, 105, 7180-7182. 
10. Kominami, H.; Nishimune, H.; Ohita, Y.; Arakawa, Y.; Inaba, T. Photocatalytic hydrogen formation from ammonia and methyl amine in an aqueous suspension of metal-loaded titanium(IV) oxide particles. Appl. Catal. B 2012, 111-112, 297-302.

11. Klare, M.; Scheen, J.; Vogelsang, K.; Jacobs, H.; Broekaert, J.A.C. Degradation of short-chain alkyl- and alkanolamines by $\mathrm{TiO}_{2}$ - and $\mathrm{Pt} / \mathrm{TiO}_{2}$-assisted photocatalysis. Chemosphere 2000, 41, 353-362.

12. Zheng, X.-J.; Wei, L.-F.; Zhang, Z.-H.; Jiang, Q.-J.; Wei, Y.-J.; Xie, B.; Wei, M.-B. Research on photocatalytic $\mathrm{H}_{2}$ production from acetic acid solution by $\mathrm{Pt} / \mathrm{TiO}_{2}$ nanoparticles under UV irradiation. Int. J. Hydrog. Energy 2009, 34, 9033-9041.

13. Helali, S.; Puzenat, E.; Perol, N.; Safi, M.-J.; Guillard, C. Methylamine and dimethylamine photocatalytic degradation-Adsorption isotherms and kinetics. Appl. Catal. A 2011, 402, 201-207.

14. Chiarello, G.L.; Aguirre, M.H.; Selli, E. Hydrogen production by photocatalytic steam reforming of methanol on noble metal-modified $\mathrm{TiO}_{2}$. J. Catal. 2010, 273, 182-190.

15. Al-Mazroai, L.S.; Bowker, M.; Davies, P.; Dickinson, A.; Greaves, J.; James, D.; Millard, L. The photocatalytic reforming of methanol. Catal. Today 2007, 122, 46-50.

16. Kim, S.; Choi, W. Kinetics and Mechanisms of Photocatalytic Degradation of $\left(\mathrm{CH}_{3}\right)_{n} \mathrm{NH}_{4-n}{ }^{+}$ $(0 \leq n \leq 4)$ in $\mathrm{TiO}_{2}$ Suspension: The Role of $\mathrm{OH}$ Radicals. Environ. Sci. Technol. 2002, 36, 2019-2025.

17. Helali, S.; Dappozze, F.; Horikoshi, S.; Bui, T.H.; Perol, N.; Guillard, C. Kinetics of the photocatalytic degradation of methylamine: Influence of $\mathrm{pH}$ and UV-A/UV-B radiant fluxes. J. Photochem. Photobiol. A 2013, 255, 50-57.

18. Daskalaki, V.D.; Kondarides, D.I. Efficient production of hydrogen by photo-induced reforming of glycerol at ambient conditions. Catal. Today 2009, 144, 75-80.

19. Bahruji, H.; Bowker, M.; Davies, P.R.; Pedrono, F. New insights into the mechanism of photocatalytic reforming on $\mathrm{Pd} / \mathrm{TiO}_{2}$. Appl. Catal. B 2011, 107, 205-209.

20. Yang, Y.Z.; Chang, C.-H.; Idriss, H. Photo-catalytic production of hydrogen from ethanol over $\mathrm{M} / \mathrm{TiO}_{2}$ catalyst $(\mathrm{M}=\mathrm{Pd}, \mathrm{Pt}$, and Rh). Appl. Catal. B 2006, 67, 217-222.

21. Guillard, C. Photocatalytic degradation of butanoic acid: Influence of its ionisation state on the degradation pathway: Comparison with $\mathrm{O}_{3} / \mathrm{UV}$ process. J. Photochem. Photobiol. A 2000, 135, $65-75$.

22. Fu, X.; Long, J.; Wang, X.; Leung, Y.; Ding, Z.; Wu, L.; Zhang, Z.; Li, Z.; Fu, X. Photocatalytic reforming of biomass: A systematic study of hydrogen evolution from glucose solution. Int. J. Hydrog. Energy 2008, 33, 6484-6491.

23. Ohtani, B.; Kakimoto, M.; Nishimoto, S.; Kagiya, T. Photocatalytic reaction of neat alcohols by metal-loaded titanium(IV) oxide particles. J. Photochem. Photobiol. A 1993, 70, 265-272.

24. Kennedy, J.C., III; Datye, A.K. Photothermal heterogeneous oxidation of ethanol over Pt/TiO 2 . J. Catal. 1998, 179, 375-389.

(C) 2014 by the authors; licensee MDPI, Basel, Switzerland. This article is an open access article distributed under the terms and conditions of the Creative Commons Attribution license (http://creativecommons.org/licenses/by/3.0/). 